\title{
European storminess and associated circulation weather types: future changes deduced from a multi-model ensemble of GCM simulations
}

\author{
Markus G. Donat ${ }^{1, *}$, Gregor C. Leckebusch ${ }^{1}$, Joaquim G. Pinto ${ }^{2}$, Uwe Ulbrich ${ }^{1}$ \\ ${ }^{1}$ Institute for Meteorology, Freie Universität Berlin, Carl-Heinrich-Becker-Weg 6-10, 12165 Berlin, Germany \\ ${ }^{2}$ Institute for Geophysics and Meteorology, University of Cologne, Kerpener Str. 13, 50923 Cologne, Germany
}

\begin{abstract}
A range of possible changes in the frequency and characteristics of European wind storms under future climate conditions was investigated on the basis of a multi-model ensemble of 9 coupled global climate model (GCM) simulations for the 20th and 21st centuries following the IPCC SRES A1B scenario. A multi-model approach allowed an estimation of the (un)certainties of the climate change signals. General changes in large-scale atmospheric flow were analysed, the occurrence of wind storms was quantified, and atmospheric features associated with wind storm events were considered. Identified storm days were investigated according to atmospheric circulation, associated pressure patterns, cyclone tracks and wind speed patterns. Validation against reanalysis data revealed that the GCMs are in general capable of realistically reproducing characteristics of European circulation weather types (CWTs) and wind storms. Results are given with respect to frequency of occurrence, storm-associated flow conditions, cyclone tracks and specific wind speed patterns. Under anthropogenic climate change conditions (SRES A1B scenario), increased frequency of westerly flow during winter is detected over the central European investigation area. In the ensemble mean, the number of detected wind storm days increases between 19 and $33 \%$ for 2 different measures of storminess, only 1 GCM revealed less storm days. The increased number of storm days detected in most models is disproportionately high compared to the related CWT changes. The mean intensity of cyclones associated with storm days in the ensemble mean increases by about $10( \pm 10) \%$ in the Eastern Atlantic, near the British Isles and in the North Sea. Accordingly, wind speeds associated with storm events increase significantly by about $5( \pm 5) \%$ over large parts of central Europe, mainly on days with westerly flow. The basic conclusions of this work remain valid if different ensemble contructions are considered, leaving out an outlier model or including multiple runs of one particular model.
\end{abstract}

KEY WORDS: European wind storms - Anthropogenic climate change $\cdot$ Multi-model ensemble Uncertainty $\cdot$ Circulation weather types $\cdot$ Extra-tropical cyclones $\cdot$ Future climate scenarios

\section{INTRODUCTION}

Mid-latitude wind storms are the most loss-relevant natural hazard in central Europe, causing $53 \%$ of economic and $64 \%$ of insured losses in Germany (Munich Re 1999, 2007). It is, thus, of high public and economic interest to quantify and understand long-term changes in their intensity and frequency in the recent past, and to estimate potential future changes induced by anthropogenic climate change (ACC).
With respect to the past century, studies investigating trends of European storm activity produce partly ambiguous results. Some indicate that no reliable longterm trends can be identified and that an increased storm activity in recent decades (e.g. Leckebusch et al. 2008a) prior to the 1990s could be partially due to natural variability (Bärring \& von Storch 2004, Matulla et al. 2008). Alexandersson et al. (2000) document that another period of high storm activity (similar to the 1990s) occurred in the late 19th century. Recently, Wang et al. 
(2009) identified positive trends of storminess for specific regions of the Northeast Atlantic when only the winter season was considered.

Analysing windstorms under future ACC, published results seem to agree better, at least with respect to European storm risk: Knippertz et al. (2000) found an increase in extreme wind events for Europe, associated with a rising number of deep cyclones towards the end of the 21st century. Leckebusch et al. (2006) investigated cyclone activity and extreme wind speeds in a multi-model ensemble and found increased activity of extreme cyclones for western parts of central Europe. For one particular climate model (ECHAM5), Bengtsson et al. (2006) found increased cyclone intensity over parts of the eastern North Atlantic (cf. their Fig. 10). Pinto et al. (2007b) demonstrated that the simulated change in storms in this model is associated with alterations of the flow characteristics over the North Atlantic, in particular an extension of the upper tropospheric jet stream into Europe. Lambert \& Fyfe (2006) analysed cyclone counts in an ensemble of 15 climate models and found an increased number of extreme cyclones in winter in both hemispheres and a slightly reduced total cyclone number with increased greenhouse gas (GHG) forcing in all models.

Considering large-scale atmospheric conditions associated with the occurrence of storms, a relation with a positive phase of the North Atlantic Oscillation (NAO) pattern has been found in different studies (e.g. Raible 2007, Pinto et al. 2009). On the other hand, the cyclones themselves play a major role in steering the NAO phase (e.g. Benedict et al. 2004, Schneidereit et al. 2007). Focusing on storms affecting central Europe, moderate positive NAO phases have been identified as optimal for the occurrence of such events (Donat et al. 2009). Studies on possible future changes in NAO under ACC conditions often reveal a shift to a more positive phase, as documented by Stephenson et al. (2006) considering a GCM ensemble.

Examining model projections of future climate, climate scientists are faced with different uncertainties which can be grouped into sensitivity to the initial conditions and to boundary conditions, model uncertainties and uncertainty due to internal variability (statistical uncertainty). Model uncertainty can be explored by using multi-model ensembles. On the seasonal timescale, multi-model performance is superior to single-model performance (Hagedorn et al. 2005). Also for climate-timescale applications, a multi-model ensemble can be favourable to a single model (cf. Palmer \& Räisänen 2002, Räisänen 2007, Collins 2007, Tebaldi \& Knutti 2007, Donat et al. 2010). Multimodel ensembles sample initial conditions and parameter uncertainties as well as structural uncertainties in the model design.
The aim of this study was to learn about potential future changes in large-scale flow conditions over central Europe under ACC conditions, in particular with respect to storm frequencies, intensities and characteristics. The robustness of the climate change signals is estimated on the basis of a multi-model ensemble of state-of-the-art coupled global climate models. This allows the avoidance of specific uncertainties in the signal arising from the use of only a single model and the presentation of a range of possible changes. The present study adds several new aspects to recent studies investigating future changes in the climatologies of extratropical cyclones (cf. Leckebusch et al. 2006, Lambert \& Fyfe 2006, Pinto et al. 2007b) or extreme wind speeds (cf. Leckebusch \& Ulbrich 2004, Pinto et al. 2007a, Gastineau \& Soden 2009). It explores changes in the frequency of wind storm events and flow types, also investigating the atmospheric conditions that are explicitly associated with the occurrence of wind storms. Thus, the robustness of the climate change signals is discussed on the basis of multi-model simulations and additionally by comparing them to different analysis methods from the aforementioned studies.

This paper is organised as follows. The data and methods are described in Section 2. Validation of 20th century simulations and analyses of future changes in large-scale flow, occurrence of storm days and related atmospheric patterns are presented in Section 3, as well as a discussion of impacts of different ensemble compositions on the results. In Section 4 the results are discussed in comparison with previous studies and Section 5 summarizes the most important conclusions from our study.

\section{DATA AND METHODS}

As almost all synoptic-scale wind storm events associated with severe damage occur during boreal winter (Klawa \& Ulbrich 2003, Munich Re 2007), our analyses concern the period from October to March. Investigations presented in this study are based on an ensemble of 9 GCM simulations with 6 different GCMs (ENSEMBLES project setup, Table 1). From each simulation, we considered a period representing recent GHG forcing conditions during the last decades of the 20th century (20C) and a projection of future climate at the end of the 21st century according to the SRES A1B scenario (A1B). The simulations of recent climate were validated against results from ERA40 reanalyses (Uppala et al. 2005), as presented in a recent study (cf. Donat et al. 2009). The length of the available simulation periods differed between the model simulations (Table 1), in particular for the A1B forcing period. Climate esti- 
Table 1. ENSEMBLES GCM simulation data included in this study. 20C: 20th century

\begin{tabular}{|c|c|c|c|c|c|c|}
\hline Model & Institute & $\begin{array}{l}\text { Resolution in } \\
\text { the atmosphere }\end{array}$ & $20 \mathrm{C}$ & SRES A1B & $\begin{array}{l}\text { No. of } \\
\text { runs }\end{array}$ & Source \\
\hline BCCR-BCM2 & Bjerkness Centre for Climate Research & T63, L45 & 1960-1999 & $2080-2099$ & 1 & Furevik et al. (2003) \\
\hline CNRM-CM3 & $\begin{array}{l}\text { Météo France/Centre National de } \\
\text { Recherches Météorologiques }\end{array}$ & T63, L31 & $1981-2000$ & $2081-2100$ & 1 & $\begin{array}{l}\text { D. Salas-Mélia et al. (2005) } \\
\text { (pers. comm.) }\end{array}$ \\
\hline DMI-ECHAM5 & Danish Meteorological Institute & T63, L31 & $1961-2000$ & $2071-2100$ & 1 & Jungclaus et al. (2006) \\
\hline FUB-EGMAM & $\begin{array}{l}\text { Freie Universität Berlin, } \\
\text { Institut für Meteorologie }\end{array}$ & T30, L39 & $1961-2000$ & $2081-2100$ & 1 & $\begin{array}{l}\text { Manzini \& McFarlane (1998) } \\
\text { Legutke \& Voss (1999) } \\
\text { Huebener et al. (2007) }\end{array}$ \\
\hline IPSL-CM4 & Institut Pierre Simon Laplace & $2.5^{\circ} \times 3.75^{\circ}, \mathrm{L} 19$ & $1961-2000$ & $2071-2100$ & 1 & Marti et al. (2005) \\
\hline MPI-ECHAM5 & Max Planck Institute for Meteorology & T63, L31 & $1961-2000$ & $2071-2100$ & 3 & Jungclaus et al. (2006) \\
\hline $\begin{array}{l}\text { METO-HC- } \\
\text { HadGEM1 }\end{array}$ & UK Met Office, Hadley Center & $\begin{array}{l}1.25^{\circ} \times 1.875^{\circ} \\
\mathrm{L} 38\end{array}$ & $1960-1999$ & $2070-2099$ & 1 & $\begin{array}{l}\text { Johns et al. (2006), Martin et } \\
\text { al. (2006), Ringer et al. (2006) }\end{array}$ \\
\hline
\end{tabular}

mates computed over relatively short periods (20 yr) may be affected by multidecadal variability, which is produced inherently by the GCMs (and which is also present in the real world). Bearing in mind that this effect may cause differences between individual simulations, the considered ensemble of in total $340 \mathrm{yr}$ of $20 \mathrm{C}$ climate and $240 \mathrm{yr}$ of A1B scenario simulations should have provided a stable basis for our investigations. Data at high temporal resolution (instantaneous $6 \mathrm{~h}$ mean sea level pressure [MSLP] fields), as required for the cyclone tracking approach, were available from the simulations carried out in the ENSEMBLES project. We could not extend our database to the larger set of CMIP3 models (stored at PCMDI, Program for Climate Model Diagnosis and Intercomparison), as they do not archive the high resolution data for periods of 2 or more decades.

Mean sea level pressure (MSLP) data and daily maximum wind speeds were used for the analyses in this study. The daily maximum wind speed is stored in almost all data sets as the wind speed maximum of all integration time steps. However, this quantity is not available for the DMI-ECHAM5OM1, BCCR-BCM2 and CNRM-CM3 simulations. For these 3 data sets, we derived the daily maximum as the maximum value of 4 instantaneous values from 00, 06, 12 and 18 UTC. This maximum of 4 instantaneous values only slightly lower than the actual maximum (cf. Pinto et al. 2007a).

The ensemble of GCM simulations considered here is dominated by the ECHAM5 model (4 of the 9 simulations are based on this model), and the results could be biased owing to the dominance of this particular model. As we preferred to include as many GCM simulations as possible in our ensemble, we generally took all 9 available simulations into account to compute the ensemble mean, because the change signals from the individual realisations obtained with ECHAM5 reveal a considerable spread. Nevertheless, the results are also discussed for the case that only one of the
ECHAM5 simulations contributes to the ensemble (cf. Section 3.6).

In a previous study, the relation between wind storm occurrence in central Europe, large-scale flow and associated atmospheric structures (i.e. related cyclones, patterns of MSLP and wind fields) was investigated on the basis of ERA40-reanalysis data (Donat et al. 2009; hereafter D09). The same methodologies and thresholds are used here (see below). Large-scale atmospheric circulation is classified into daily circulation weather types (CWTs, see Jones et al. 1993). This methodology was used to examine storm events in the central European investigation area (D09), and is suitable for processing the large amounts of data in a multi-model ensemble. The only required input parameter is the daily mean MSLP field. To classify the large-scale flow characteristics, directional flow and vorticity are calculated using the geostrophic wind approximation based on the MSLP differences around the central point (grid points used for the CWT calculation are shown in Fig. 1). On the basis of these terms, flow is classified into directional, (anti)cyclonal or hybrid CWTs. The directional types are divided into 8 sectors of $45^{\circ}$ : NE, E, SE, S, SW, W, NW and N. For each day, flow can thus be classified into 1 of 27 types (8 directional, 1 cyclonal [C], 1 anti-cyclonal [AC], 8 hybrid cyclonal-directional, 8 hybrid anti-cyclonaldirectional and 1 undefined). For the CWT counts, the hybrid weather types are considered as half occurrence of directional flow and half occurrence of (anti) cyclonal flow. Thus, the frequencies of a total of 11 classes are determined (8 directional, 1 cyclonal, 1 anticyclonal, 1 undefined). Further details can be found in Jones et al. (1993). Here, the investigation area is centred over central Europe $\left(50^{\circ} \mathrm{N}, 10^{\circ} \mathrm{E}\right.$; cf. Fig. 1). Gale days are detected based on a gale index:

$$
G=\sqrt{\left(F^{2}+\left(\frac{1}{2} Z\right)^{2}\right)}
$$


(unit: $\mathrm{hPa}$ ) that considers strength of directional flow $(F)$ and vorticity $(Z)$. With a threshold of $G>35$, a reasonable number of severe gale days for the central European investigation area is detected, based on ERA40 reanalysis (D09). For reasons of comparability, this threshold is also used here to analyse the GCM simulations. Gale days based on this definition are hereafter denoted as JC35.

In contrast to this criterion for storm day identification, which is based only on characteristics of largescale flow (and does not explicitly take into account the incidence of strong winds), a second criterion considering the occurrence of extreme wind speeds is applied. The local 98th percentile of daily maximum wind speeds is deemed to be a common threshold for occurrence of storm damage (e.g. Klawa \& Ulbrich 2003, Leckebusch et al. 2007, Pinto et al. 2007a) and is thus also used here as a threshold for the identification of storm events. If it is exceeded in at least $25 \%$ of the central European investigation area (dashed black box in Fig. 1) the day is classified as a storm day. The relative definition of the threshold in this criterion assures comparability in 2 respects: it permits comparison of different GCMs even if the absolute wind speeds have a systematic bias. It also allows the models to be considered simultaneously in spite of the different wind values used (maximum of 4 instantaneous values or highest simulated value on a day). The $25 \%$ of area requirement is checked by counting the number of central European grid boxes depending on the spatial resolution. In ERA40 (horizontal resolution $\sim 1.125^{\circ}$ ), the investigation area for storm detection consists of 49 grid boxes, so the local 98th percentile criterion must be fulfilled in at least 12 grid boxes on the same day. In ECHAM5 $\left(\sim 1.9^{\circ}\right)$, the spatial threshold is 4 out of 16 grid boxes, and in the coarsest model (FUB-EGMAM, $\sim 4^{\circ}$ ) it is only 1 out of 4 grid boxes. Hereafter, SP98 is used as an acronym for wind storm days identified based on the exceedance of the 98th percentile of daily maximum wind speeds.

Cyclone systems are identified and their pathways are tracked by means of an objective algorithm developed by Murray \& Simmonds (1991) and adapted to Northern Hemisphere (NH) cyclone characteristics (Pinto et al. 2005). It is based on $6 \mathrm{~h}$ MSLP fields and organized in 2 steps: at first, cyclones are identified by searching for the maximum of the Laplacian of the MSLP $\left(\nabla^{2} p\right)$. Under quasi-geostrophic conditions, this is equivalent to the search for extremes of relative vorticity. Subsequently, a tracking algorithm is applied, which takes into account the most probable displacement of the cyclone core under the given large-scale conditions and previous path and speed. Tracks with a lifetime shorter than $24 \mathrm{~h}$ are removed in a further step. While this tracking methodology is only one of many currently available (cf. Ulbrich et al. 2009), it performs well in comparison to other similar methods (Raible et al. 2008). In addition to previous studies (Pinto et al. 2007b, Leckebusch et al. 2008b), cyclone tracks are explicitly associated to storm events in central Europe. This is done by searching for the most intensive cyclone passing across the cyclone detection box that is calibrated to 0 to $20^{\circ} \mathrm{E}, 47$ to $65^{\circ} \mathrm{N}$ (solid box in Fig. 1) during an identified storm day.

\section{ANALYSIS OF THE MODEL SIMULATIONS}

\subsection{Winter mean MSLP field and atmospheric flow}

As air flow on the scale considered here is primarily a consequence of pressure gradients, this section concentrates on the analysis of MSLP patterns. For 20C forcing, the winter mean MSLP field of the GCM simulations (Fig. 2a, ensemble mean of 9 GCM runs) reproduces the characteristic pattern with low pressure from the mean Icelandic low to the North Sea and high pressure over the Azores and southern Europe, as has also been found using ERA40 reanalysis data (cf. D09, their Fig. 6). In the area of the mean Icelandic low as well as in the high pressure zone over the Azores, absolute pressure values are slightly higher in the multi-model ensemble mean compared to ERA40 (Fig. 2b). The Azores high in the multi-model mean additionally extends further eastwards than observed, leading to a significantly higher MSLP over the whole Mediterranean region. The mean pressure near the British

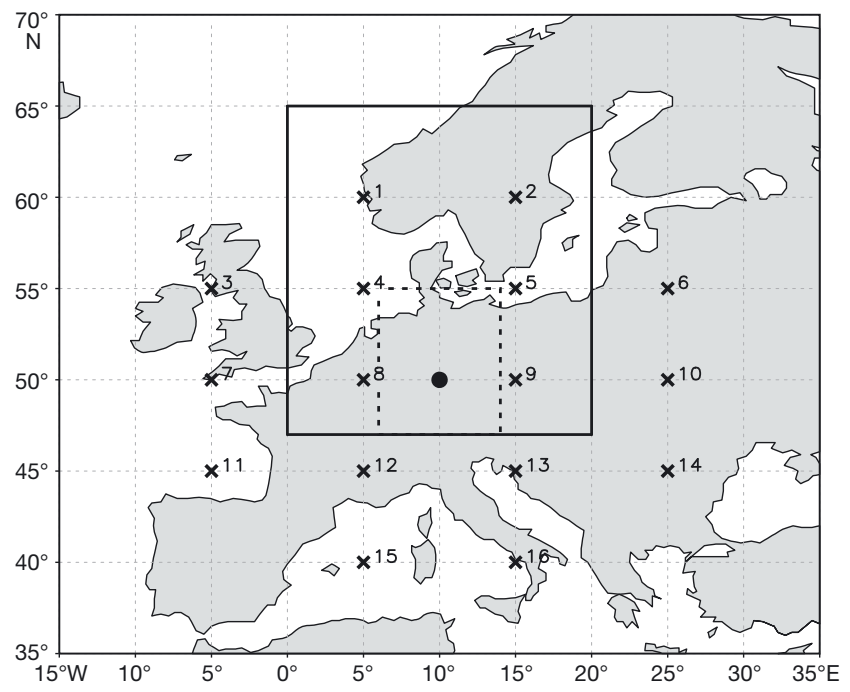

Fig. 1. Investigation areas for classification of CWTs and gale days (16 points, marked ' $\mathbf{X}$ ', for calculation of the geostrophic flow at the black central point), detection of storm days exceeding the 98th percentile of daily maximum wind speed (SP98) (dashed box) and for the assignment of cyclone tracks to the wind storm days (solid box) 


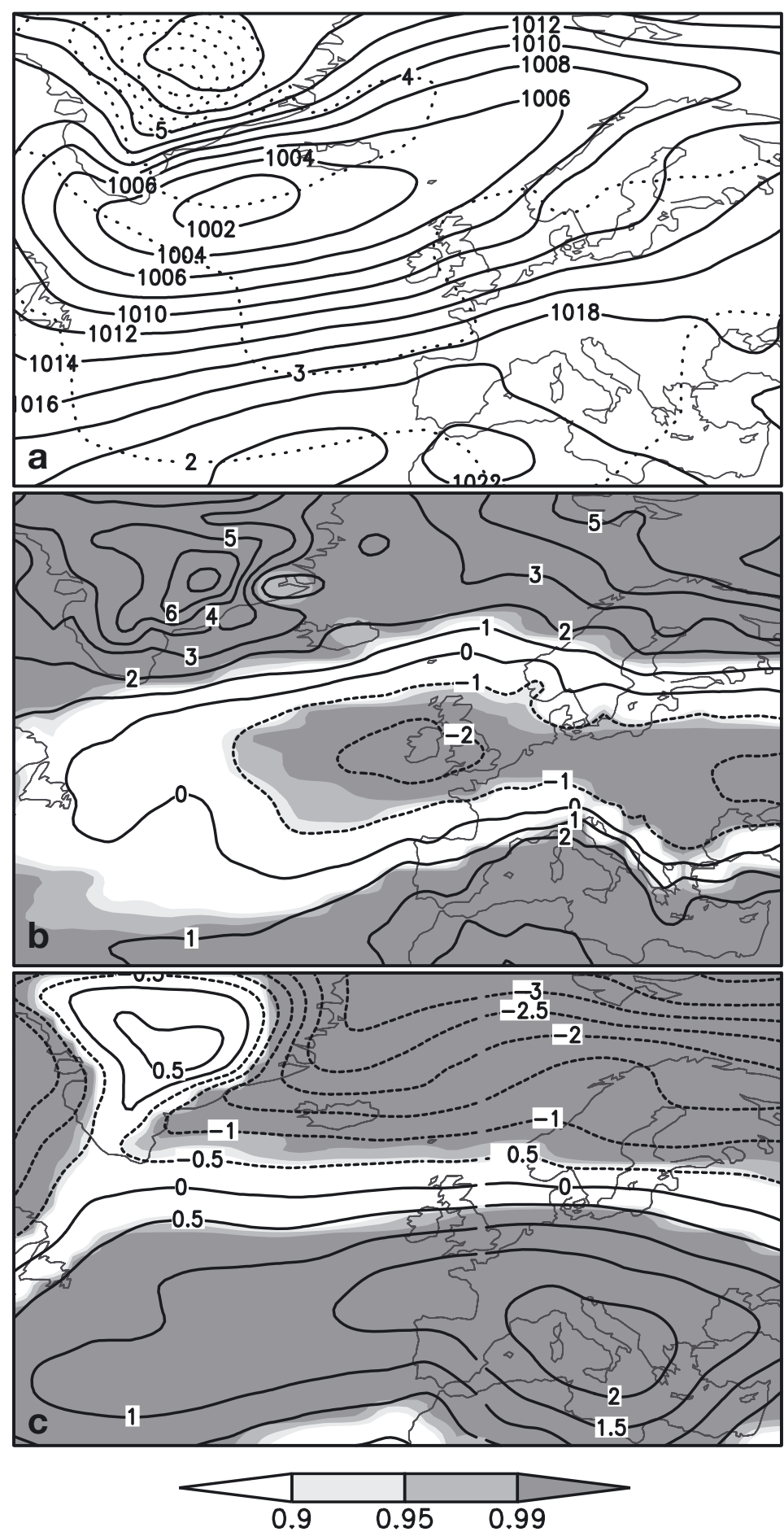

Fig. 2. Average mean sea level pressure (MSLP) fields during the winter half year (October to March). (a) GCM ensemble mean (solid lines) of the 20th century (20C) simulations (unit: $\mathrm{hPa}$ ). The inter-model standard deviation between the fields in the different ensemble members is indicated by the dotted lines. (b) Difference between the GCM ensemble mean for $20 \mathrm{C}$ and the ERA40 reanalysis. The magnitude of differences is displayed by contour lines (unit: $\mathrm{hPa}$ ), significance level by shading (Student's $t$-test). (c) ACC signal GCM ensemble mean A1B minus 20C. Differences are displayed by contour lines (unit: $\mathrm{hPa}$ ), significance level by shading (Student's $t$-test)
Isles is marginally too low (reaching $-2 \mathrm{hPa}$ ). Consequently, the meridional pressure gradient over central and western Europe is stronger in the climate model simulations than in ERA40 reanalysis; thus, mean westerly flow is, on average, expected to be enhanced in the GCMs. For example, the mean pressure difference between northern Scotland and northern Spain is about $20 \%$ higher in the GCM ensemble compared to ERA40.

The MSLP fields of the individual models (not shown) reveal that higher pressure values over the Mediterranean leading to overly strong pressure gradients over central Europe are found especially in the simulations with IPSL-CM4 (here, mean MSLP is about $5 \mathrm{hPa}$ too high over southern Europe), CNRM-CM3, BCCR-BCM2 and FUB-EGMAM. The other 2 models (HadGEM1, ECHAM5) reproduce the characteristic climatological pressure patterns that are relevant for central Europe better.

The changes in the mean pressure field in simulations for the end of the 21st century (following the SRES A1B scenario) are shown in Fig. 2c. The ensemble mean reveals significantly enhanced pressure values (by up to $2.5 \mathrm{hPa}$ ) over large areas of southern Europe and significantly decreased pressure over northern Europe (by $-3 \mathrm{hPa}$ ). This leads to a higher meridional pressure gradient over central and western Europe compared to simulations of the recent climate. Consequently, an increase in mean westerly flow may be expected as part of the climate signal.

A similar climate change signal can be found in almost all individual model simulations (not shown), leading to a high statistical significance of the change signal in the ensemble mean ( $p>0.99$ in terms of interannual variability over large parts of the Mediterranean and southern Europe, according to a local Student's $t$-test). As expected from the lower number of years in the individual models' signals, the individual changes in general have a lower statistical significance.

Signals fundamentally different from the ensemble mean and the majority of the ensemble members are found in the simulations with HadGEM1 and IPSL-CM4. In the HadGEM1 simulation, the pattern of change is shifted northwards: maximum increase of pressure is found over the Bay of Biscay; decreasing pressure can only be detected in the very north of Scandinavia. The IPSL-CM4 shows an essentially contrary signal com- 
pared to the model ensemble. Here, MSLP is greater over the Northern Atlantic and over large areas of the European continent. MSLP values are lower over the Atlantic south of $40^{\circ} \mathrm{N}$. Consequently, the mean meridional pressure gradient over Europe is reduced in this model for enhanced GHG forcing.

The increased winter mean meridional pressure gradient over western and central Europe in most of the individual GHG runs and in the ensemble mean indicates a change to a more positive mean state of the NAO (as e.g. discussed by Stephenson et al. 2006), resulting in a more westerly mean large-scale flow. To analyse the flow characteristics for single days and especially for storm events, an objective scheme for classifying daily circulation weather types is applied in the next step.

\subsection{Classification of daily circulation weather types}

The relative frequencies of the different CWTs during the winter half year (October to March) are presented in Table 2 for ERA40 reanalysis and for the GCM 20C simulations. In the reanalysis data (cf. D09), days with anticyclonic flow occur most frequently $(31.6 \%)$, followed by westerly $(22.6 \%)$ and cyclonal $(10.0 \%)$ flow. Atmospheric flow from the whole easterly sector (NE, E, SE) is relatively rare during winter. To analyse the agreement between the ERA40- and the GCM-derived CWT frequencies for the presentday forcing periods, we use the root mean square error (RMSE) as a measure of agreement (column 15 in Table 2). RMSE is calculated on the basis of the differences between the individual class frequencies in each model, in comparison to ERA40. HadGEM1 shows the best agreement with reanalysis (RMSE $=1.2 \%$ ), whereas IPSL-CM4 (5.6\%) and CNRM-CM3 (8.2\%) show the largest discrepancies. Nearly all GCM simulations show an overestimated number of days with westerly or cyclonal flow, whereas the frequency of anticyclonic days is underestimated by all models but HadGEM1. Particularly IPSL-CM4 and CNRM-CM3 (the 2 GCMs with the highest RMSE) show a conspicuously overestimated frequency of westerly flow days.

Ensemble mean frequencies of the different CWTs were calculated by averaging the results from all considered GCMs (Fig. 3a, last row of Table 2) and reveal a generally good agreement with the ECMWF reanalysis under present-day forcing (20C), but with an underestimation of AC flow frequency and an overestimation of flow from the whole westerly sector.

For the GHG forcing period at the end of the 21st century, all simulations (except for IPSL-CM4) reveal a significantly enhanced frequency of westerly flow (Table 3), which is in line with the winter mean MSLP signals mentioned in Section 3.1. Further, all simulations show reduced frequency of cyclonal flow and, with the exception of HadGEM1, also of easterly flow days. This is also true if changes for the whole easterly sector (NE, E, SE) are added up. In the ensemble mean - as in the majority of the regarded modelsthere is a significantly increased frequency of westerly flow (relative change $+16 \%$ ), and less frequent occurrences of cyclonal $(-21 \%)$ and easterly flow $(-27 \%)$.

\subsection{Storm day frequencies}

With respect to the occurrence of storms under present-day forcing conditions, the ensemble average frequency of gale days (JC35 criterion) is realistic (about $7 \%$ higher than in ERA40). Individual models range between $40 \%$ (BCCR-BCM2) and 120\% (MPIECHAM5, run 1) of the observational gale day fre-

Table 2. Relative frequencies of circulation weather type (CWT) classes and storm days in ERA40 and GCM 20th century simulations (unit: percent of d during winter, October to March). The Root Mean Square Error (RMSE) was calculated for each model based on the 11 CWT classes counts (columns 2 to 12), in comparison with the respective class frequency in ERA40. JC35: gale days; SP98: wind storm days. U: CWT undefined; see Section 2 for other abbreviations

\begin{tabular}{|c|c|c|c|c|c|c|c|c|c|c|c|c|c|c|}
\hline & $\mathrm{C}$ & $\mathrm{AC}$ & NE & E & SE & $\mathrm{S}$ & SW & $\mathrm{W}$ & NW & $\mathrm{N}$ & $\mathrm{U}$ & $\mathrm{JC} 35$ & SP98 & RMSE \\
\hline ERA40 & 10.0 & 31.6 & 1.9 & 6.9 & 4.9 & 3.3 & 9.5 & 22.6 & 5.5 & 1.4 & 2.5 & 3.0 & 3.0 & \\
\hline MPI-ECHAM5OM1 r1 & 12.6 & 25.4 & 2.3 & 5.3 & 4.8 & 3.6 & 10.5 & 25.0 & 6.6 & 1.7 & 2.2 & 3.6 & 3.5 & 2.3 \\
\hline MPI-ECHAM5OM1 r2 & 13.2 & 25.7 & 2.1 & 4.9 & 4.3 & 3.9 & 11.1 & 24.1 & 6.8 & 1.8 & 2.1 & 3.3 & 3.4 & 2.3 \\
\hline MPI-ECHAM5OM1 r3 & 13.0 & 26.3 & 2.0 & 4.1 & 3.8 & 4.5 & 11.7 & 24.5 & 6.6 & 1.5 & 1.9 & 3.5 & 3.5 & 2.3 \\
\hline IPSL-CM4 & 9.9 & 21.9 & 1.6 & 2.7 & 1.7 & 2.1 & 11.5 & 36.9 & 8.3 & 1.9 & 1.6 & 6.7 & 3.5 & 5.6 \\
\hline FUB-EGMAM & 12.4 & 21.8 & 2.2 & 3.3 & 2.3 & 2.8 & 11.7 & 29.8 & 9.7 & 2.3 & 1.6 & 2.4 & 4.5 & 4.2 \\
\hline DMI-ECHAM5OM1 & 13.0 & 26.2 & 2.4 & 5.2 & 5.2 & 3.9 & 10.5 & 22.9 & 6.7 & 1.7 & 2.1 & 3.4 & 3.4 & 2.0 \\
\hline CNRM-CM3 & 14.5 & 14.0 & 1.3 & 2.8 & 2.2 & 2.0 & 11.5 & 42.1 & 6.0 & 1.1 & 2.5 & 1.8 & 3.5 & 8.2 \\
\hline BCCR-BCM2 & 18.1 & 18.0 & 2.5 & 5.6 & 3.7 & 3.6 & 10.7 & 26.0 & 6.7 & 1.6 & 3.3 & 1.2 & 3.1 & 5.0 \\
\hline HadGEM1 & 9.4 & 30.4 & 1.9 & 6.2 & 3.7 & 2.8 & 10.8 & 25.5 & 4.8 & 1.2 & 3.3 & 3.3 & 3.2 & 1.2 \\
\hline Ensemble mean $( \pm \mathrm{SD})$ & $\begin{array}{c}12.9 \\
( \pm 2.5)\end{array}$ & $\begin{array}{c}23.3 \\
( \pm 5.0)\end{array}$ & $\begin{array}{c}2.0 \\
( \pm 0.4)\end{array}$ & $\begin{array}{c}4.5 \\
( \pm 1.3)\end{array}$ & $\begin{array}{c}3.5 \\
( \pm 1.2)\end{array}$ & $\begin{array}{c}3.2 \\
( \pm 0.9)\end{array}$ & $\begin{array}{c}11.1 \\
( \pm 0.5)\end{array}$ & $\begin{array}{c}28.5 \\
( \pm 6.6)\end{array}$ & $\begin{array}{c}6.9 \\
( \pm 1.4)\end{array}$ & $\begin{array}{c}1.6 \\
( \pm 0.4)\end{array}$ & $\begin{array}{c}2.3 \\
( \pm 0.6)\end{array}$ & $\begin{array}{c}3.2 \\
( \pm 1.5)\end{array}$ & $\begin{array}{c}3.5 \\
( \pm 0.4)\end{array}$ & 3.4 \\
\hline
\end{tabular}



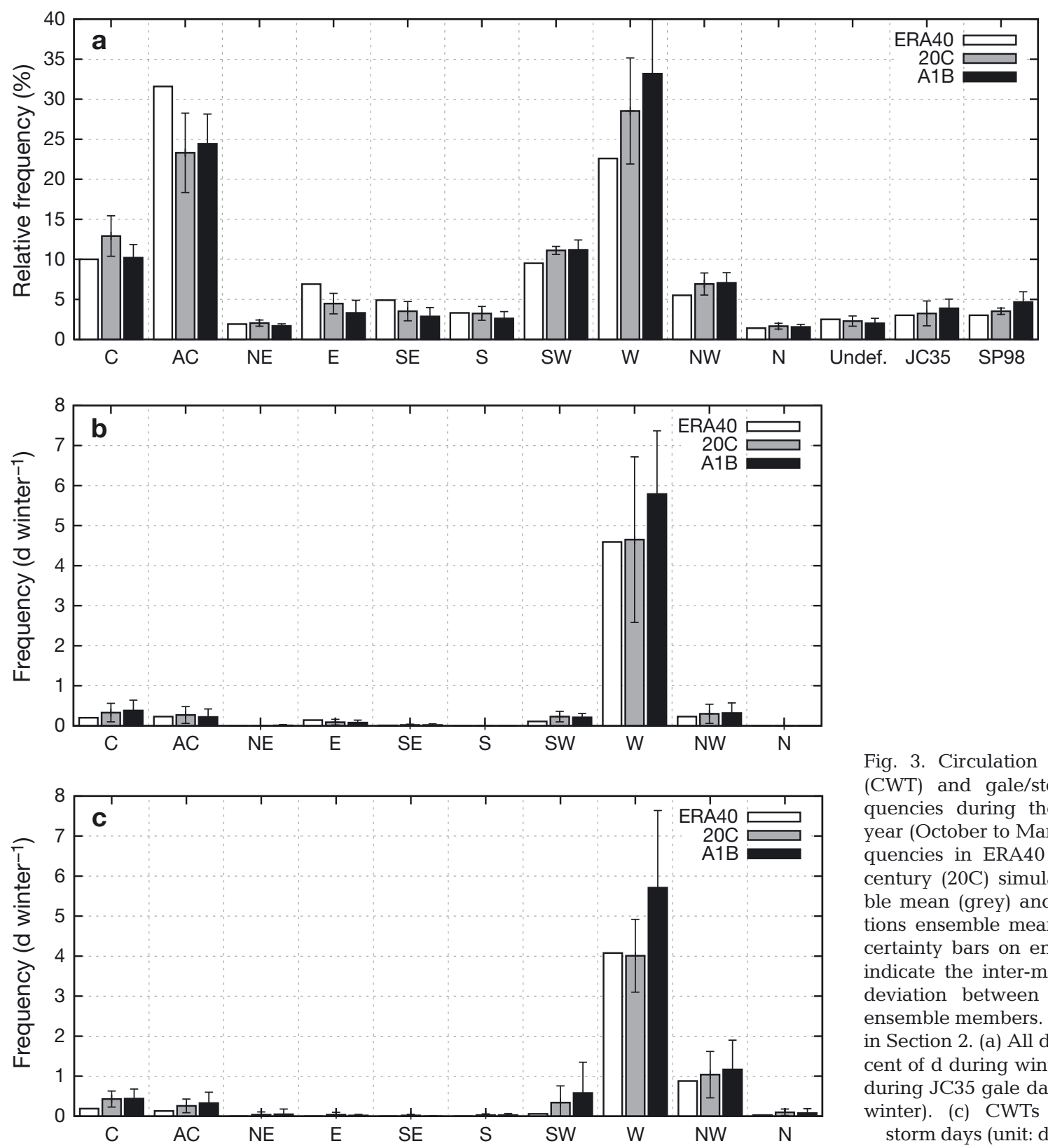

Fig. 3. Circulation weather type (CWT) and gale/storm day frequencies during the winter half year (October to March). Bars: frequencies in ERA40 (white), 20th century (20C) simulations ensemble mean (grey) and A1B simulations ensemble mean (black). Uncertainty bars on ensemble mean indicate the inter-model standard deviation between the different ensemble members. Abbreviations in Section 2. (a) All days (unit: percent of d during winter). (b) CWTs during JC35 gale days (unit: d per winter). (c) CWTs during SP98 storm days (unit: $d$ per winter)

quency, except for the IPSL-CM4 simulation which produces more than twice the ERA40 value (Table 2). Using the SP98 method, a somewhat higher ensemble mean frequency of storms is obtained, compared to JC35 (17\% more than ERA40, cf. Table 2, Fig. 3a). The differences between storm frequencies produced using the 2 criteria are large for some of the simulations, whereas the number of storm days had been found to be about equal between JC35 and SP98 using the ERA40 data (D09). For SP98, the inter-model differences are much smaller than for JC35. This is because the relative wind speed threshold used in the definition of SP98 is exceeded (by definition) in $2 \%$ of days in the present-day climate in any single model and grid box.

Almost all ensemble members show an enhanced frequency of gale days in the A1B forcing period. In the ensemble mean, a relative increase of JC35 of about 19 percent is detected (Table 3, column 13, Fig. 3a). Only IPSL-CM4 shows a relative decrease in gale days $(-15 \%)$. This is in agreement with the winter mean flow signal, which is in opposition to all other simulations considered. For this GCM, the A1B gale frequency is thus close to the respective numbers for the other runs. This contributes to a reduced model spread of JC35 in the future climate period (cf. Fig. 3a). 
Table 3. Climate change signals A1B minus 20C of CWT classes and storm days in the ensemble of GCMs. Bold: changes on a significance level higher than 0.90 (Student's $t$-test). JC35: gale days; SP98: wind storm days; U: CWT undefined

\begin{tabular}{|c|c|c|c|c|c|c|c|c|c|c|c|c|c|}
\hline & $\mathrm{C}$ & $\mathrm{AC}$ & $\mathrm{NE}$ & $\mathrm{E}$ & $\mathrm{SE}$ & $\mathrm{S}$ & SW & W & NW & $\mathrm{N}$ & $\mathrm{U}$ & JC35 & SP98 \\
\hline MPI-ECHAM5_1 & -2.0 & +1.1 & -0.8 & -2.0 & -1.6 & -0.3 & +1.4 & +4.3 & +0.4 & -0.2 & -0.2 & +1.0 & +1.4 \\
\hline MPI-ECHAM5_2 & -1.9 & +0.1 & -0.2 & -1.7 & -1.0 & -0.8 & +1.2 & +4.8 & -0.2 & -0.2 & -0.2 & +0.6 & +0.8 \\
\hline MPI-ECHAM5_3 & -0.6 & -2.1 & +0.1 & -0.3 & -0.4 & -0.7 & -0.6 & +4.2 & -0.1 & +0.3 & +0.3 & +0.7 & +0.1 \\
\hline IPSL-CM4 & -1.5 & +4.8 & 0 & -0.7 & +0.4 & +0.5 & +0.3 & -2.7 & -0.9 & -0.2 & -0.1 & -1.1 & -0.3 \\
\hline FUB-EGMAM & -3.1 & -0.6 & -0.7 & -0.7 & -0.7 & -1.5 & +1.1 & +7.4 & 0 & -0.4 & -0.7 & +1.4 & +3.0 \\
\hline DMI-ECHAM5 & -2.5 & +2.0 & -0.6 & -2.6 & -2.2 & -0.7 & +0.1 & +5.4 & +1.3 & +0.2 & -0.1 & +0.6 & +0.5 \\
\hline CNRM-CM3 & -6.7 & +5.6 & -0.1 & -1.1 & -1.1 & -0.6 & -1.5 & +6.3 & -0.1 & -0.2 & -0.7 & +2.3 & +1.8 \\
\hline BCCR-BCM2 & -5.8 & +0.7 & -0.7 & -2.2 & -0.6 & -1.2 & +0.6 & +10.0 & +0.3 & -0.2 & -0.7 & +0.1 & +1.0 \\
\hline HadGEM & -0.3 & -1.6 & -0.3 & +0.9 & +1.2 & -0.4 & -2 & +2.1 & +0.6 & 0 & -0.2 & 0 & +2.1 \\
\hline Ensemble mean $( \pm \mathrm{SD})$ & $\begin{array}{c}-2.7 \\
( \pm 2.2)\end{array}$ & $\begin{array}{c}+1.1 \\
( \pm 2.7)\end{array}$ & $\begin{array}{c}-0.4 \\
( \pm 0.3)\end{array}$ & $\begin{array}{c}-1.2 \\
( \pm 1.1)\end{array}$ & $\begin{array}{l}-0.7 \\
( \pm 1.0)\end{array}$ & $\begin{array}{c}-0.6 \\
( \pm 0.6)\end{array}$ & $\begin{array}{c}+0.1 \\
( \pm 1.2)\end{array}$ & $\begin{array}{c}+4.6 \\
( \pm 3.5)\end{array}$ & $\begin{array}{c}+0.1 \\
( \pm 0.6)\end{array}$ & $\begin{array}{c}-0.1 \\
( \pm 0.2)\end{array}$ & $\begin{array}{c}-0.3 \\
( \pm 0.3)\end{array}$ & $\begin{array}{c}+0.6 \\
( \pm 0.9)\end{array}$ & $\begin{array}{c}+1.2 \\
( \pm 1.0)\end{array}$ \\
\hline
\end{tabular}

Considering change signals of SP98 storm days, the $98 \%$ wind speed threshold of the individual $20 \mathrm{C}$ climate is also maintained for the future periods. In terms of vulnerability assessment due to extreme wind speeds, this corresponds to an approach without adaptation of loss thresholds to changed climatic conditions (cf. Leckebusch et al. 2007; Pinto et al. 2007a). The occurrence of SP98 storm days is enhanced in 8 out of 9 ensemble simulations (significant at the $90 \%$ level in 6 of them [Student's t-test], cf. Table 3, column 14). Only the IPSL-CM4 reveals a decrease in storminess (though not significant). In the ensemble mean, the number of SP98 storm days shows an increase of about $33 \%$ (Fig. 3a).

\subsection{Atmospheric circulation on storm days}

A clear dominance of storm days with westerly flow is found for the ensemble of the 20C GCM simulations, using both the JC35 (Fig. 3b, Table 4) and the SP98 criterion (Fig. 3c, Table 4). This agrees well with results based on ERA40 reanalysis data (cf. D09). Note that for easier interpretation, frequencies of storm days in Table 4 are given in d per winter half year. The simulated role of several other CWTs is partly different from the ERA40 estimates (with respect to both JC35 and SP98). Note, however, that the number of occurrences is still small compared to westerly flow.

The changes in storm day frequencies in the future scenario simulations are almost exclusively linked with changed frequency of storms with westerly flow (SP98: Table 4, Fig. 3c). According to the JC35 method, the ensemble mean storm day frequency is enhanced by $19 \%$; considerable changes are only found for storm days with $\mathrm{W}$ flow (Table 4, Fig. 3b). Also considering the individual ensemble members, the number of JC35 gale days with flow from the west is significantly increased in 6 simulations; in 5 of them by approximately 20 percent. In CNRM-CM3 it is even doubled. Only IPSL-CM4 shows (in conjunction with the reduced total frequency of gale days, cf. Section 3.3.) a significant decrease in those gale days with westerly flow. In 2 ensemble members (HadGEM1 and BCCR-BCM2), only small and non-significant changes are detected.

With the SP98 detection method, a strongly enhanced total number of storm days found in the ensemble mean $(+33 \%)$ as well as in almost all ensemble members (Table 4 ) is again linked with changed numbers of storm days with westerly flow. In 7 out of 9 ensemble members, significantly more storm days with flow from the west are detected. Most of the models show an increase of about 30 to 50 percent in this class; a small and non-significant reduction is only found in IPSL-CM4.

The enhanced storm day frequency is only partly explained by the CWT frequency changes. If the ratio of storm days in each CWT class remained unchanged for the future scenario climate, changes in CWT frequencies would contribute to relative increases of only $11 \%$ (9\%) for JC35 (SP98), compared to the identified total increases of $19 \%(33 \%)$. An additional contribution comes from changing ratios of storm days in the different CWT classes. For example, considering the most relevant westerly flow class, the percentage of storm days in all days (irrespective of whether they are storm days or not) increases in the ensemble mean from 9.4 to $10.1 \%$ using the JC35 criterion and from 7.9 to $9.5 \%$ for SP98 (corresponding to relative increases of 7 and $20 \%$, respectively). This result agrees with that of Pinto et al. (2010), who provided evidence that the frequency of intense storms within their storm clusters significantly increases in future climate conditions for the ECHAM5 runs. 
Table 4. Gale days in ERA40, in the 20th century simulations (20C) and changes in the scenario simulations (A1B minus 20C), occurring in the different circulation weather type (CWT) classes (unit: $d$ per winter). The last column shows the total number of gale days (i.e. the sum of days in the different classes). U: CWT undefined; see Section 2 for abbreviations. Bold: changes at a significance level >0.90 (Student's $t$-test)

\begin{tabular}{|c|c|c|c|c|c|c|c|c|c|c|c|c|}
\hline & $\mathrm{C}$ & $\mathrm{AC}$ & $\mathrm{NE}$ & $\mathrm{E}$ & $\mathrm{SE}$ & $\mathrm{S}$ & SW & W & NW & $\mathrm{N}$ & $\mathrm{U}$ & Total \\
\hline \multicolumn{13}{|l|}{$\begin{array}{l}\text { ERA } 40 \text { and } 20 \mathrm{C} \\
\mathrm{JC} 35 \text { : }\end{array}$} \\
\hline ERA40 & 0.20 & 0.23 & - & 0.14 & 0.01 & - & 0.11 & 4.59 & 0.23 & - & - & 5.50 \\
\hline MPI-ECHAM5_1 & 0.61 & 0.34 & 0.01 & 0.16 & 0.04 & 0.03 & 0.23 & 4.89 & 0.25 & - & - & 6.55 \\
\hline MPI-ECHAM5_2 & 0.41 & 0.18 & - & 0.11 & 0.06 & - & 0.16 & 4.75 & 0.40 & - & - & 6.08 \\
\hline MPI-ECHAM5_3 & 0.50 & 0.34 & - & 0.01 & 0.04 & - & 0.40 & 4.76 & 0.40 & - & - & 6.45 \\
\hline IPSL-CM4 & 0.25 & 0.79 & - & 0.14 & 0.03 & - & 0.44 & 9.63 & 0.86 & - & - & 12.13 \\
\hline FUB-EGMAM & 0.24 & 0.16 & 0.01 & 0.03 & - & - & 0.30 & 3.29 & 0.25 & - & - & 4.28 \\
\hline DMI-ECHAM5 & 0.71 & 0.26 & - & 0.19 & 0.05 & - & 0.29 & 4.36 & 0.36 & - & - & 6.23 \\
\hline CNRM-CM3 & 0.03 & 0.05 & - & - & - & - & 0.05 & 3.13 & 0.05 & - & - & 3.30 \\
\hline BCCR-BCM2 & 0.15 & 0.09 & - & 0.06 & - & - & 0.09 & 1.68 & 0.06 & - & - & 2.13 \\
\hline HadGEM & 0.05 & 0.20 & - & 0.11 & - & - & 0.13 & 5.39 & 0.08 & - & - & 5.95 \\
\hline Ensemble mean $( \pm \mathrm{SD})$ & $\begin{array}{c}0.33 \\
( \pm 0.23)\end{array}$ & $\begin{array}{c}0.27 \\
( \pm 0.21)\end{array}$ & $\begin{array}{c}- \\
( \pm 0.01)\end{array}$ & $\begin{array}{c}0.09 \\
( \pm 0.07)\end{array}$ & $\begin{array}{c}0.02 \\
( \pm 0.02)\end{array}$ & $\begin{array}{c}- \\
( \pm 0.01)\end{array}$ & $\begin{array}{c}0.23 \\
( \pm 0.13)\end{array}$ & $\begin{array}{c}4.65 \\
( \pm 2.07)\end{array}$ & $\begin{array}{c}0.30 \\
( \pm 0.24)\end{array}$ & - & $\begin{array}{l}- \\
-\end{array}$ & $\begin{array}{c}5.90 \\
( \pm 2.65)\end{array}$ \\
\hline \multicolumn{13}{|l|}{ SP98: } \\
\hline ERA40 & 0.19 & 0.13 & - & - & - & - & 0.06 & 4.08 & 0.88 & 0.03 & - & 5.35 \\
\hline MPI-ECHAM5_1 & 0.70 & 0.24 & 0.01 & 0.01 & - & 0.09 & 0.13 & 3.43 & 1.63 & 0.13 & - & 6.35 \\
\hline MPI-ECHAM5_2 & 0.54 & 0.16 & 0.06 & - & 0.04 & 0.05 & 0.11 & 3.51 & 1.49 & 0.11 & - & 6.08 \\
\hline MPI-ECHAM5_3 & 0.45 & 0.21 & 0.05 & 0.01 & 0.03 & - & 0.18 & 3.54 & 1.61 & 0.20 & 0.03 & 6.30 \\
\hline IPSL-CM4 & 0.23 & 0.15 & - & - & 0.01 & 0.08 & 0.21 & 4.90 & 0.65 & 0.03 & - & 6.25 \\
\hline FUB-EGMAM & 0.24 & 0.56 & - & - & - & - & 0.61 & 5.18 & 1.40 & 0.06 & - & 8.05 \\
\hline DMI-EH5OM1 & 0.63 & 0.10 & 0.05 & - & 0.03 & 0.04 & 0.19 & 3.51 & 1.36 & 0.23 & - & 6.13 \\
\hline CNRM-CM3 & 0.58 & 0.28 & - & 0.13 & 0.08 & 0.03 & 0.13 & 4.45 & 0.70 & - & - & 6.35 \\
\hline BCCR-BCM2 & 0.46 & 0.53 & 0.21 & 0.16 & - & 0.03 & 1.38 & 2.53 & 0.10 & 0.14 & - & 5.53 \\
\hline HadGEM & 0.10 & 0.14 & - & 0.03 & - & - & 0.11 & 5.04 & 0.39 & 0.03 & - & 5.83 \\
\hline Ensemble mean $( \pm \mathrm{SD})$ & $\begin{array}{c}0.43 \\
( \pm 0.20)\end{array}$ & $\begin{array}{c}0.26 \\
( \pm 0.17)\end{array}$ & $\begin{array}{c}0.04 \\
( \pm 0.07)\end{array}$ & $\begin{array}{c}0.04 \\
( \pm 0.06)\end{array}$ & $\begin{array}{c}0.02 \\
( \pm 0.03)\end{array}$ & $\begin{array}{c}0.03 \\
( \pm 0.03)\end{array}$ & $\begin{array}{c}0.34 \\
( \pm 0.42)\end{array}$ & $\begin{array}{c}4.01 \\
( \pm 0.91)\end{array}$ & $\begin{array}{c}1.04 \\
( \pm 0.58)\end{array}$ & $\begin{array}{c}0.10 \\
( \pm 0.08)\end{array}$ & $\begin{array}{c}- \\
( \pm 0.01)\end{array}$ & $\begin{array}{c}6.32 \\
( \pm 0.70)\end{array}$ \\
\hline \multicolumn{13}{|l|}{$\begin{array}{l}\text { A1B minus 20C } \\
\text { JC35: }\end{array}$} \\
\hline MPI-ECHAM5_1 & 0.07 & -0.14 & -0.01 & -0.10 & 0.06 & -0.03 & 0.03 & 1.61 & 0.38 & - & - & 1.88 \\
\hline MPI-ECHAM5_2 & -0.13 & -0.08 & - & -0.01 & -0.06 & - & 0.10 & 1.32 & -0.18 & - & - & 0.96 \\
\hline MPI-ECHAM5_3 & 0.13 & -0.12 & - & 0.12 & -0.02 & - & -0.25 & 1.42 & -0.13 & - & - & 1.15 \\
\hline IPSL-CM4 & 0.17 & -0.05 & 0.05 & 0.01 & 0.01 & - & -0.04 & -2.16 & -0.08 & - & - & -2.09 \\
\hline FUB-EGMAM & 0.14 & -0.01 & -0.01 & - & 0.03 & - & -0.03 & 2.49 & 0.03 & - & - & 2.63 \\
\hline DMI-ECHAM5 & 0.02 & -0.03 & - & -0.07 & -0.02 & - & -0.10 & 1.30 & 0.04 & - & - & 1.14 \\
\hline CNRM-CM3 & - & 0.13 & - & 0.03 & - & - & 0.05 & 4.10 & -0.05 & - & - & 4.25 \\
\hline BCCR-BCM2 & -0.05 & -0.04 & - & -0.06 & - & - & 0.01 & 0.38 & 0.04 & - & - & 0.28 \\
\hline HadGEM & 0.10 & -0.05 & - & 0.02 & - & - & 0.01 & -0.22 & 0.09 & - & - & -0.05 \\
\hline Ensemble mean $( \pm \mathrm{SD})$ & $\begin{array}{c}0.05 \\
( \pm 0.10)\end{array}$ & $\begin{array}{l}-0.04 \\
( \pm 0.08)\end{array}$ & $\begin{array}{c}0.00 \\
( \pm 0.02)\end{array}$ & $\begin{array}{c}-0.01 \\
( \pm 0.06)\end{array}$ & $\begin{array}{c}0.00 \\
( \pm 0.03)\end{array}$ & $\begin{array}{c}0.00 \\
( \pm 0.01)\end{array}$ & $\begin{array}{c}-0.02 \\
( \pm 0.10)\end{array}$ & $\begin{array}{c}1.14 \\
( \pm 1.74)\end{array}$ & $\begin{array}{c}0.01 \\
( \pm 0.16)\end{array}$ & - & $\begin{array}{l}- \\
-\end{array}$ & $\begin{array}{c}1.13 \\
( \pm 1.77)\end{array}$ \\
\hline \multicolumn{13}{|l|}{ SP98: } \\
\hline MPI-ECHAM5_1 & 0.17 & 0.03 & 0.02 & -0.01 & 0.00 & 0.03 & 0.01 & 1.74 & 0.38 & 0.16 & - & 2.52 \\
\hline MPI-ECHAM5_2 & 0.10 & -0.05 & -0.06 & 0.03 & -0.04 & -0.02 & 0.04 & 1.14 & 0.15 & 0.07 & - & 1.36 \\
\hline MPI-ECHAM5_3 & 0.07 & -0.03 & -0.05 & -0.01 & -0.03 & 0.02 & -0.08 & 1.03 & -0.55 & -0.08 & -0.03 & 0.27 \\
\hline IPSL-CM4 & 0.06 & 0.12 & - & - & - & -0.08 & 0.22 & -0.67 & -0.15 & -0.03 & - & -0.52 \\
\hline FUB-EGMAM & 0.06 & 0.44 & - & - & - & - & 0.91 & 3.65 & 0.40 & -0.06 & - & 5.40 \\
\hline DMI-EH5OM1 & 0.03 & 0.03 & -0.05 & 0.02 & -0.01 & - & -0.05 & 0.60 & 0.50 & -0.09 & - & 0.98 \\
\hline CNRM-CM3 & -0.18 & - & - & -0.13 & -0.08 & - & 0.18 & 3.88 & -0.43 & - & - & 3.25 \\
\hline BCCR-BCM2 & -0.31 & -0.15 & 0.19 & -0.06 & - & -0.03 & 0.88 & 1.55 & -0.05 & -0.14 & - & 1.88 \\
\hline HadGEM & 0.10 & 0.20 & - & 0.03 & - & - & 0.07 & 2.43 & 0.91 & -0.03 & - & 3.71 \\
\hline Ensemble mean $( \pm \mathrm{SD})$ & $\begin{array}{c}0.01 \\
( \pm 0.15)\end{array}$ & $\begin{array}{c}0.07 \\
( \pm 0.17)\end{array}$ & $\begin{array}{c}0.01 \\
( \pm 0.07)\end{array}$ & $\begin{array}{l}-0.02 \\
( \pm 0.05)\end{array}$ & $\begin{array}{l}-0.02 \\
( \pm 0.03)\end{array}$ & $\begin{array}{l}-0.01 \\
( \pm 0.03)\end{array}$ & $\begin{array}{c}0.24 \\
( \pm 0.38)\end{array}$ & $\begin{array}{c}1.71 \\
( \pm 1.44)\end{array}$ & $\begin{array}{c}0.13 \\
( \pm 0.47)\end{array}$ & $\begin{array}{l}-0.02 \\
( \pm 0.09)\end{array}$ & $\begin{array}{c}- \\
( \pm 0.01)\end{array}$ & $\begin{array}{c}2.09 \\
( \pm 1.84)\end{array}$ \\
\hline
\end{tabular}




\subsection{Cyclone tracks, pressure patterns and local wind speeds associated with storm events}

Simulated atmospheric features in relation to JC35 and SP98 storm events, such as associated cyclone tracks and wind speed patterns during the identified storm days, generally agree with those found for reanalysis data, in particular the maximum wind speeds over the North Sea and the Baltic Sea (Fig. 4a \& b, compare D09, their Fig. 5) and the decrease towards lower wind speeds over inland areas. The latter is, however, more pronounced than in ERA40. Additionally, the isotachs over inland areas in the GCM ensemble have a more zonal orientation compared to ERA40. Although some of the ensemble members feature lower wind speeds (e.g. BCCR, CNRM, IPSL, not shown) and others overestimate wind speed values (e.g. FUB-EGMAM), the ensemble mean reveals a remarkable accordance of absolute wind speed values on gale days compared to ERA40 reanalysis wind speed values.

The observed track density pattern of 'storm cyclones' (i.e. cyclones related to storm days, D09, their Fig. 5c) is well reproduced in the ensemble mean of GCM 20C simulations (Fig. 4c), as well as the spatial pattern of their mean intensity. For the latter, the maximum values between Great Britain and Iceland are about $20 \%$ lower than in ERA40, whereas there is a larger area in the GCM ensemble where the mean intensity of storm cyclones has medium values over the central North Atlantic ( $\nabla^{2} p 0.8$ to $1.2 \mathrm{hPa}^{\circ}{ }^{\circ}$ at. $\left.{ }^{-2}\right)$. This difference from the reanalysis data is primarily related to the lower spatial resolution of the GCMs in comparison to the reanalysis data (cf. e.g. Pinto et al. 2006).

Even when considering the atmospheric features associated with storm days in the individual CWT classes (Fig. 5a-e), the GCM ensemble is able to reproduce the characteristics of storm events for each circulation class as found for ERA40 (cf. D09, their Fig. 7). Regarding the MSLP patterns associated with JC35 storm events for the individual CWT classes (left column in Fig. 5), agreement is expected from the definition of CWTs and storms for the central European area. Furthermore, agreement is also found for typical pathways of the storm cyclones and their intensity (middle column in Fig. 5) when assigned to the different CWT classes. For example, the ridge-like cyclone tracks and relatively high cyclone intensities over the Baltic Sea associated with high wind speeds over central Europe that were analysed for storm days with NW flow are also found in the climate model simulations. Also the wind anomalies associated with the CWTs on storm days (right column in Fig. 5, computed as deviations from the average of maximum wind speeds on all gale days shown in Fig. 4a) correspond well to the patterns
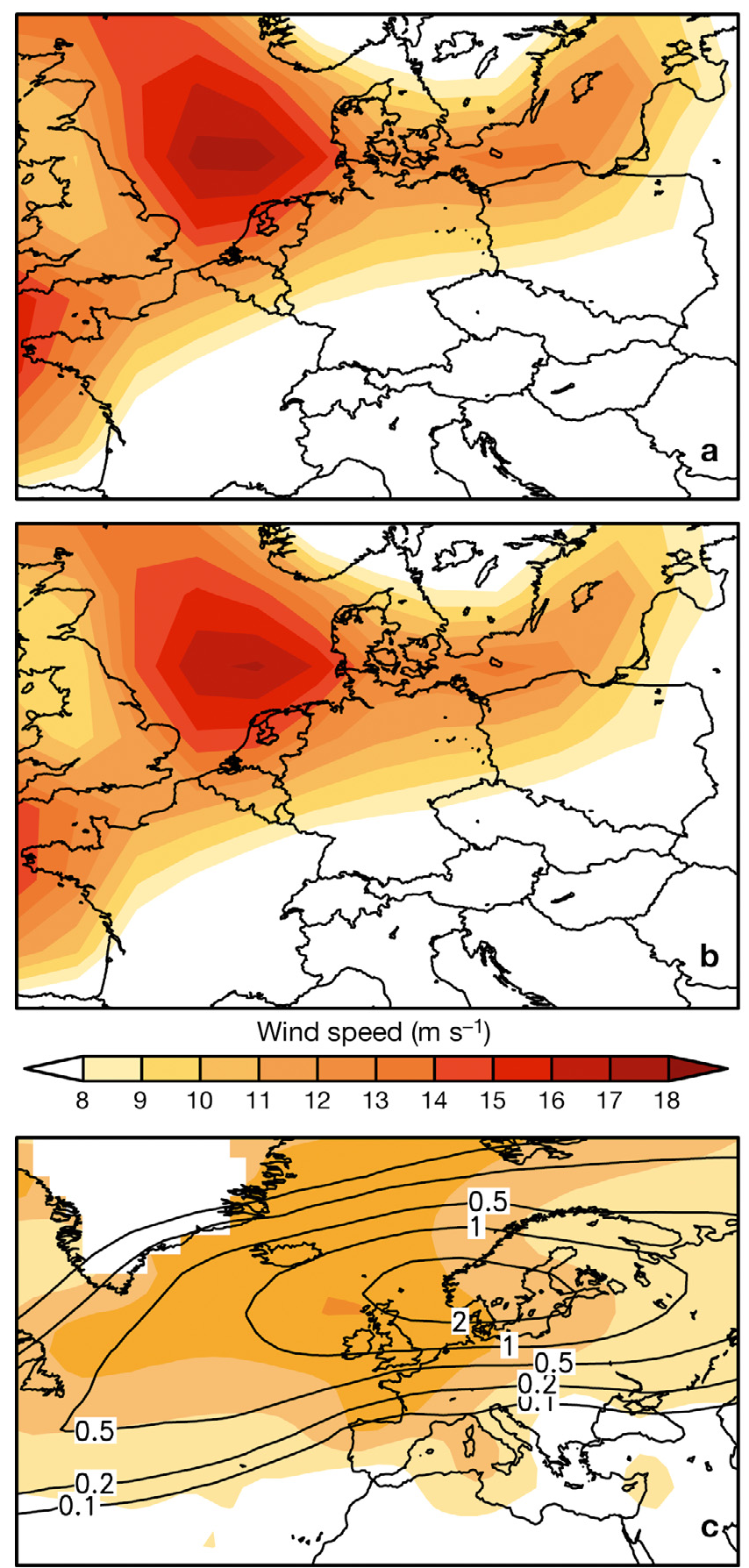

Cyclone intensity $\left(\mathrm{hPa}^{\circ}{ }^{\circ}\right.$ at. $\left.^{-2}\right)$

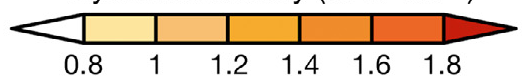

Fig. 4. Wind speeds and cyclones in relation to storm events. Mean daily maximum wind speeds during (a) JC35 gale days and (b) SP98 storm days for the ensemble mean of GCM 20C simulations. (c) Ensemble mean cyclone track density (isolines, unit: tracks per winter) and intensity (colour, $\nabla^{2} p$ ) of cyclones assigned to JC35 gale days in GCM 20C simulations. For smoothing, track density and intensity values were calculated for areas with a radius of $7.5^{\circ}$ lat. around each grid point. Colour in areas with orography above $1500 \mathrm{~m}$ is suppressed 

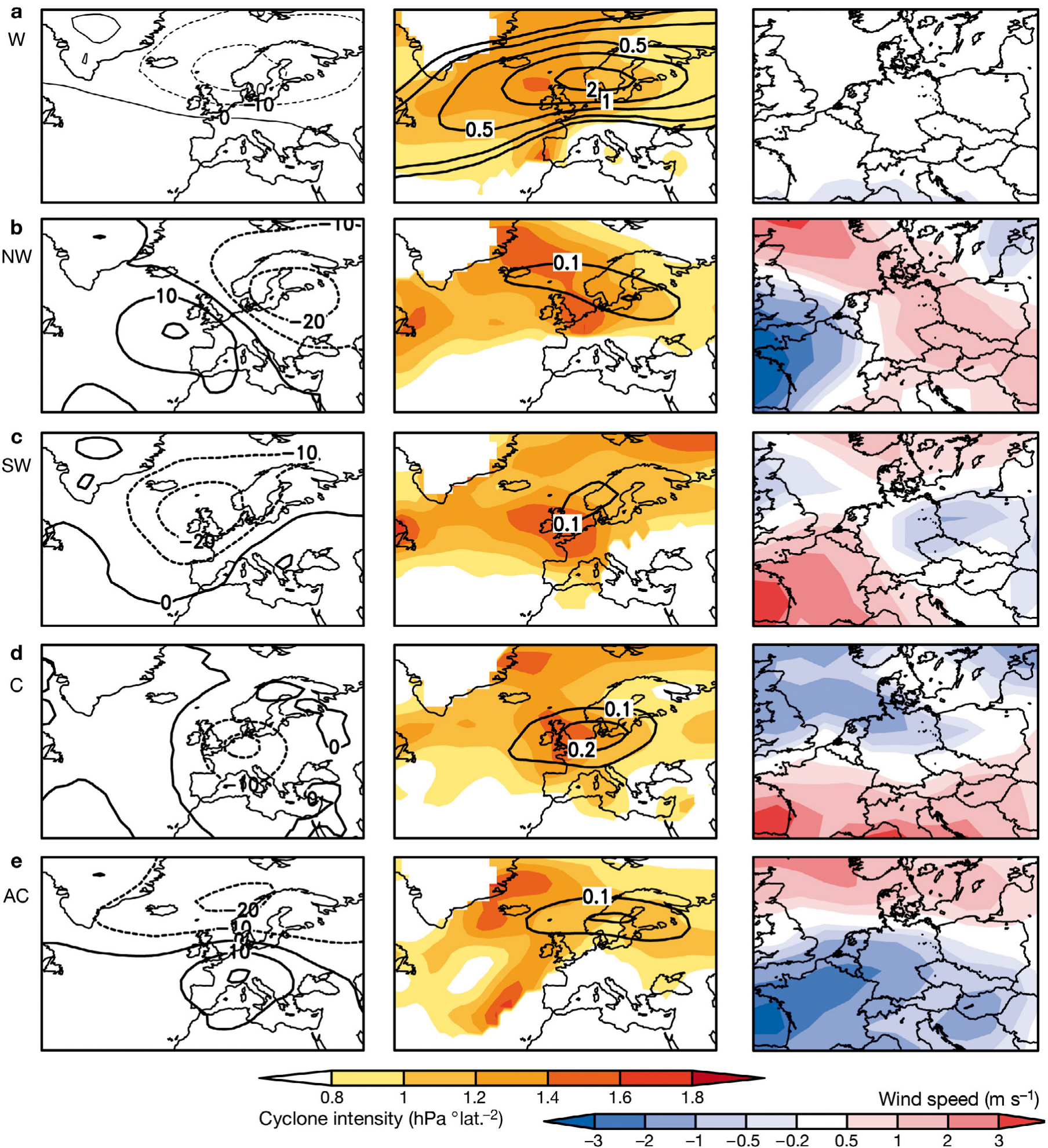

Fig. 5. Atmospheric features in relation to JC35 gale days in the ensemble of GCM 20C simulations, separated for relevant circulation weather types (CWTs): (a) W; (b) NW; (c) SW ; d) cyclonal, $\mathrm{C}_{i}$ (e) anticyclonal, AC. Left column: anomaly of the mean sea level pressure field (MSLP) for storm days in each CWT class from the mean MSLP field for winter in Fig. 1a (unit: hPa). Middle: related cyclones (black contour lines $=$ track density, unit: tracks per winter; shaded areas $=$ mean intensity of cyclones, $\nabla^{2} p$ ). For smoothing, track density and intensity values were calculated for areas with a radius of $7.5^{\circ}$ lat. around each grid point. Colour in areas with orography above $1500 \mathrm{~m}$ was suppressed. Right column: Anomaly of the mean daily maximum wind speed on storm days in each CWT class from the mean daily maximum wind speed on all storm days in Fig. 4a 
that were also found for reanalysis data (compare with D09, their Fig. 7). In particular, above-average wind speeds in large parts of central Europe were analysed for storm days with NW flow (Fig. 5b), while storm days with SW flow are associated with high wind speeds particularly over western France (Fig. 5c). The composite for storm days with cyclonic flow (Fig. 5d) reveals above-average wind speeds over southern Europe. Storm days with AC flow in central Europe (which are primarily of hybrid CWT classes with W and NW flow, respectively; cf. D09) are associated with high wind speeds particularly over Scandinavia and the northern part of the North Sea. In conclusion, this validation reveals that typical atmospheric patterns associated with storm events in reanalysis data are well reproduced by the GCM ensemble. This is valid not only with respect to CWT frequencies but also for cyclone pathways and intensities and the spatial distribution of wind speeds.

By the definition of storm cyclones, an enhanced number of gale days must be reflected in a higher number of cyclones related to storms. Regarding the A1B simulations, the track density is increased only along the maximum of track densities found for today's climate (Fig. 6a, compare to Fig. 4c). North and south of this zone, very little change is found. Thus, this analysis reveals an accentuation of cyclones related to European storms, concentrated on the characteristic pathway over the eastern North Atlantic, via the British Isles, North Sea and southern Scandinavia.

The intensity of storm cyclones (measured in terms of $\nabla^{2} p$ ) increases significantly (by up to 5-10 percent) under increased GHG forcing in a zone from the North Atlantic to western central Europe (Fig. 6b). Consequently, and in accordance with this finding, the mean of maximum wind speeds during these storm days is significantly higher by approximately 5 percent over large parts of Europe (Fig. 6c). Increased wind speeds related to storm days are found in all models at least over parts of central Europe (not shown). Even in the IPSL-CM4 simulation, where reduced frequency of storm days was analysed, the mean of daily maximum wind speed during storm events is increased (not shown).

The inter-model standard deviations of the change signals were used as a measure of uncertainty (contour lines in Fig. 6a-c). They were found to have the same order of magnitude as the ACC signals, associated with the sensitivity of the standard deviation to outlier signals (e.g. IPSL, refer to Section 3.6). In areas with maximum change signal, the uncertainty between the climate signals of the individual ensemble members also shows a maximum. Taking the boundaries given by the standard deviations as a range for likely changes, the model ensemble produces a positive wind speed signal over central Europe during JC35 gale days amounting to between 0 and $10 \%\left(0\right.$ and $\left.1 \mathrm{~m} \mathrm{~s}^{-1}\right)$. The increase of track density of cyclones associated with storm is, for example, $+0.5( \pm 0.6)$ over southern Scandinavia, i.e. between 0 and 1 tracks per yr $(0$ and $40 \%$, respectively). Similarly, the mean intensity of cyclones related to storm events in central Europe might increase between 0 and $0.2 \mathrm{hPa}^{\circ} \mathrm{lat}^{-2}$, i.e. 0 and $17 \%$ over the North Atlantic, British Isles and North Sea.

Consideration of ACC signals for the particular CWT classes reveals that changes for gale days with westerly flow correspond well to the presented change signals for all gale days (not shown). This is plausible, as the majority of storm days occur with flow from $\mathrm{W}$ and gale frequency change signals are also strongest for those gale days with W flow (Table 4, Fig. 3b,c). Atmospheric features of storms with CWT classes other than W largely show neither relevant nor significant change signals, in line with the small changes in their frequencies. Change patterns for SP98 storm days are in general similar to those analysed for JC35 (not shown).

\subsection{Effects of different model combinations on the ensemble mean ACC signals}

Multi-model studies are unequivocally affected by the construction of the ensemble. We incorporated all available simulations from the ENSEMBLES project in the GCM ensemble, which is thus dominated by the ECHAM5 model. While different realisations obtained with the same climate model (started with different initial conditions) are not expected to reveal significantly different climate mean states, consideration of extreme cyclones, extreme wind speeds or storminess, for example, may yield different magnitudes of the climate change signals (compare e.g. the A1B-20C results in Table 4 and Pinto et al. 2007b). As the development of the different realisations is not systematically identical, it appeared reasonable to consider all available simulations for this study in order to estimate the range and robustness of possible future changes. Nevertheless, we analysed the influence of different model combinations, taking only one simulation from each GCM into account. The presented ensemble mean change signals from the previous sections were recalculated, now including only one of the ECHAM5 simulations. Thus, 4 different ensembles of 6 different GCMs could be constructed (each containing either realisation 1, 2 or 3 of MPI-ECHAM5 or the DMI-ECHAM5 run).

Generally, when including only one ECHAM5 simulation in the ensemble, the mean change signals correspond well to the signals calculated on the basis of all 9 


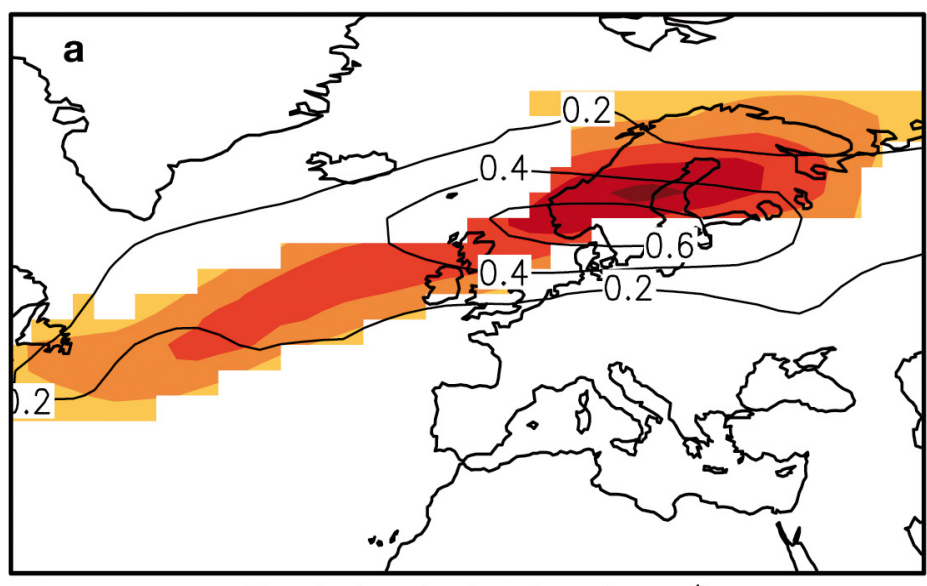

Track density (tracks winter ${ }^{-1}$ )
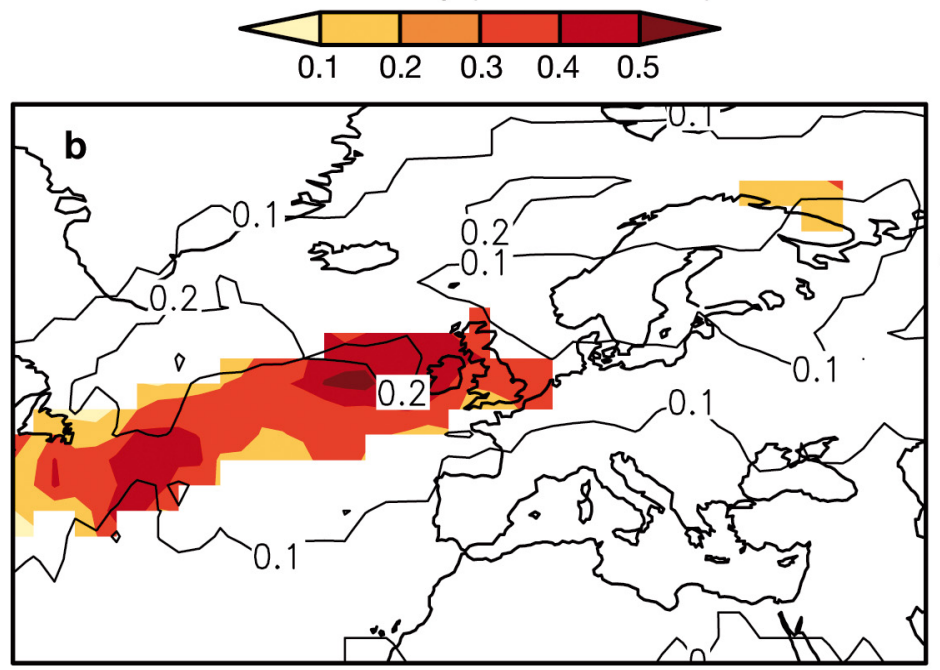

Cyclone intensity $\left(\mathrm{hPa}{ }^{\circ}\right.$ lat. $\left.{ }^{-2}\right)$
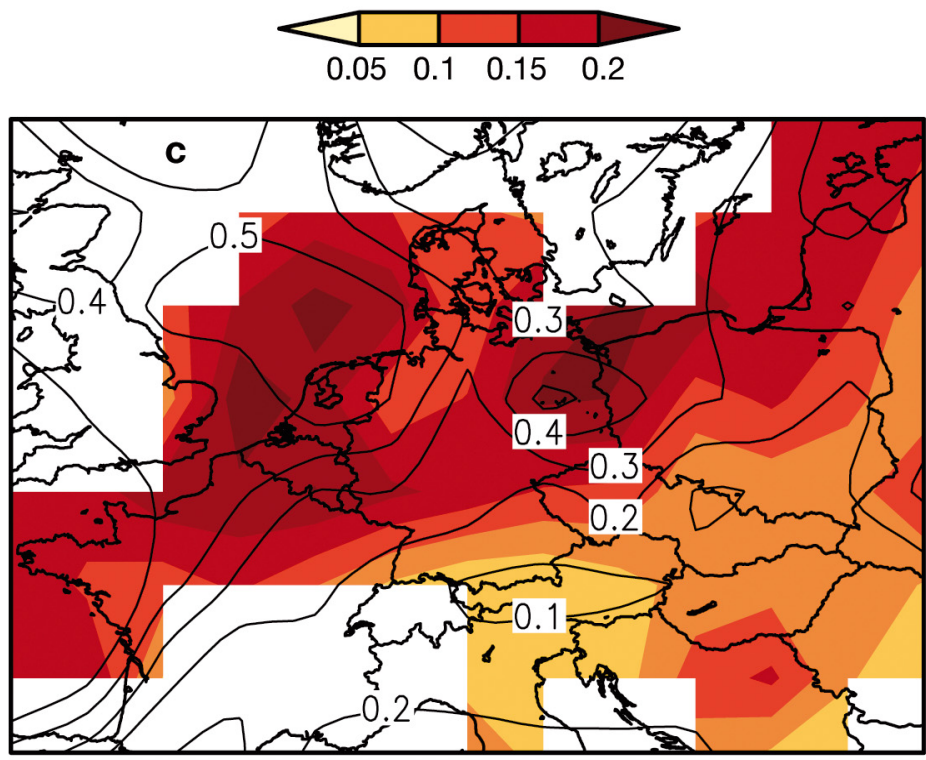

Wind speed $\left(\mathrm{m} \mathrm{s}^{-1}\right)$

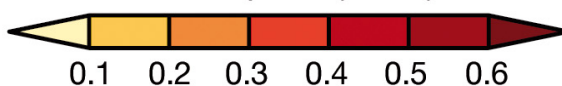

simulations, whereas the standard deviation of the different ensemble members is slightly increased. For example, the frequency of JC35 gale days would be increased by between $1.0( \pm 2.2)$ and 1.2 $( \pm 2.2)$ d per winter period (i.e. between 18 and $20 \%)$, compared to an increase of $1.1( \pm 1.8) \mathrm{d}$ per winter if all 9 simulations are included in the ensemble (cf. Table 4). The increased standard deviations in the 6-model ensembles are explained by the fact that-despite the considerable spread between the different realisations - the signals of the individual ECHAM5 simulations are all relatively close to the ensemble mean signal. This contributes to the result that the mean signals are not significantly different for the ensembles considering only one ECHAM5 simulation, whereas the inter-model uncertainty is increased.

Similar results are also found for SP98 and for the atmospheric features associated with the occurrence of wind storm days, such as track density and intensity of the related cyclones, or the composite of wind speed during storm days (compare to Fig. 6). Again, the mean change signals based on the different 6-member ensembles considering only one realisation of ECHAM5 correspond well to the ensemble mean based on all 9 available simulations, but the significance of the signals is reduced.

Additionally, the effect of removing the IPSLCM4 run from the ensemble was tested. Such an exclusion of a model from the ensemble could be justified by its performance in reproducing observed climate conditions and would correspond to a rather crude model-weighting approach. Other studies have also identified IPSL-CM4 as a rather poorly performing GCM (e.g. Reichler \& Kim 2008; van Ulden \& van Oldenborgh 2006). Here, this GCM revealed large biases regarding MSLP pat-

Fig. 6. Anthropogenic climate change A1B minus 20C for cyclones and wind speed related to JC35 gale days in the GCM ensemble. Differences are indicated by coloured areas and are only displayed for regions where the significance level is above 0.95 (according to Student's $t$-test). The inter-model standard deviation of the change signals in the different ensemble members is shown by the contour lines. (a) Track density of storm related cyclones (plotting of the change signal was omitted where track density in the $20 \mathrm{C}$ period is smaller than $\left.0.3 \mathrm{yr}^{-1}\right)$. (b) Intensity $\left(\nabla^{2} p\right)$ of cyclones related to JC35 gale days (plotting of the change signal was omitted where track density in the 20C period is smaller than $0.3 \mathrm{yr}^{-1}$ ). (c) Mean daily maximum wind speed during JC35 gale days 
tern, CWT classes and storm day frequencies for present climate conditions. With respect to the ACC signals, it is again an outlier, showing opposite signals to most other models and to the ensemble mean. Consequently, the ensemble mean signals are higher and their uncertainty reduced if IPSL-CM4 is excluded from the ensemble. For example, the frequency of JC35 gale days would be increased by $28( \pm 25) \%$, compared to $19( \pm 28) \%$ if all models are considered.

\section{DISCUSSION}

The intensification of zonal (westerly) mean flow over Europe in the scenario simulations identified here is consistent with results reported by other authors. Van Ulden \& van Oldenborgh (2005) computed largescale geostrophic flow over Europe based on monthly mean MSLP from an ensemble of IPCC AR4 models. They also found a westerly bias in winter for simulations of recent climate and a tendency towards more westerly flow in the future climate simulations. Further, Stephenson et al. (2006) investigated the response of wintertime NAO to increasing GHG concentrations in a CMIP2 multi-model ensemble. They found a positive increase in the NAO index in the majority of the models. Moreover, Pinto et al. (2007b) found a shift both to more positive NAO values and to enhanced zonal flow in ECHAM5 simulations for different forcing scenarios (B1, A1B, A2).

The increased frequency of westerly flow under increased GHG forcing, together with reduced frequency of cyclonic flow (as identified in this study), are associated with changes in cyclone activity. Leckebusch et al. (2008b) investigated the changes in $\mathrm{NH}$ cyclone climatologies for the same GCM ensemble and showed a reduced total number of cyclone tracks over large areas of $\mathrm{NH}$ at the end of the 21st century. Similar results have also been found by considering cyclone climatologies in single model studies and also smaller GCM ensembles, e.g. by Leckebusch \& Ulbrich (2004), Leckebusch et al. (2006) and Pinto et al. (2007b). The reduction in cyclone tracks is, however, stronger over southern than over northern Europe. With respect to the cyclones leading to wind storms over central Europe (which are typically travelling north of the affected area), recent climate change studies also found an increased frequency of extreme cyclones and increased mean intensity of cyclones over the eastern Atlantic (Bengtsson et al. 2006, Pinto et al. 2007b, Leckebusch et al. 2008b). In particular, Pinto et al. (2009) identified an increase in explosive cyclone developments close to Europe tracking over the North Sea into the Baltic Sea (the pathway identified here as most relevant for wind storm occurrence in central
Europe) in the 3 MPI-ECHAM5 runs also considered here. This assessment was confirmed by Della-Marta \& Pinto (2009), who used extreme value statistics to infer the changes in extreme cyclones over the North Atlantic/Europe, identifying a significant shortening of the return periods of storms over the North Sea and Baltic Sea (using the Laplacian of the MSLP as a measure of cyclone intensity). These results agree well with the conclusions of the present study.

Besides considering multi-model simulations, the present study adds to the above-mentioned studies (examining rather general cyclone climatologies) as it focuses on atmospheric features (i.e. cyclone systems, wind speeds) explicitly related to storm events in central Europe. Additionally, changes in flow class and storm day frequencies are quantified. These eventspecific ACC signals are of even higher significance than those found in the analyses of more general climatologies for extreme wind speeds or extreme cyclones based on the same GCM ensemble. A further important and new aspect in this study is the estimation of a range of possible future changes in storminess and their model-related uncertainties based on an MME of climate simulations. Results estimating the ACC are sensitive to the particular climate models considered and to the diagnostic methodologies applied (e.g. Christensen et al. 2007, Ulbrich et al. 2009). The ensemble of GCM simulations considered here reveals statistically significant ACC signals, in spite of a relatively large uncertainty that can be estimated by considering the inter-model standard deviations.

Ensemble mean results inherently depend on the ensemble composition. The present study considers 4 realisations of the ECHAM5 model $(3 \times$ MPI, $1 \times$ DMI). Although the individual climate change patterns in the 4 ECHAM5 simulations are comparable, there are some considerable differences in their magnitude (e.g. Tables 3 \& 4). We examined the impact on the ensemble results if only 1 of the 4 ECHAM5 simulations was considered, and found comparable mean signals, but increased uncertainty. This is in line with the fact that signals from all ECHAM5OM1 simulations are relatively close to the ensemble mean signal (in accordance with Ulbrich et al. 2008). Nevertheless, and for all considered ensemble mean ACC signals, the inter-model standard deviation (used here as a measure of uncertainty) is relatively large compared to the magnitude of the signal. The standard deviation is, however, strongly affected by outliers. If a model that performed rather weakly in reproducing recent climate conditions (also an outlier with respect to ACC signals) was excluded from the ensemble, stronger signals with reduced uncertainty were obtained. While these results suggest it might be useful to exclude outliers, the inclusion of as many simula- 
tions as possible is generally recommended, as it allows information about the possible spread of results based on state-of-the-art climate models to be obtained. It might also be problematic to estimate the model performance by comparing the mean climate states of relatively short periods because of internal long-term variability. A model performing well (weakly) in a specific period might be less (more) realistic in another period (Reifen \& Toumi 2009). Furthermore, the quality metric depends strongly on the considered variables (e.g. Reichler \& Kim 2008).

Uncertainty due to emissions scenarios was not considered in this study. Previous results, however, indicate that the intensity of the changes is in turn largely dependent on the intensity of the forcing (Leckebusch \& Ulbrich 2004, Pinto et al. 2007a,b). As the occurrence of storms is characterised by a high long-term variability, however, a direct response to a stronger GHG forcing is not necessarily detectable. This aspect leaves space for future studies. Also, the detected concentration of storm-related cyclones under ACC conditions within a rather narrow 'highway' remains an interesting phenomenon and requires further investigations.

A well-known weakness of current GCMs is a tendency to an overly zonal flow, related to an underestimation of anticyclonic/blocking situations (e.g. D'Andrea et al. 1998, Demuzere et al. 2009). In the present study, the largest changes were found for the westerly flow class, the frequency of which was found to be overestimated for the simulations of recent climate compared to observations-based data. On the other hand, this study shows that the typical features of those cyclones and flow classes that are related to wind storms are nevertheless well reproduced by the GCMs. This suggests that the models are capable of realistically simulating the statistics of storm events and the related atmospheric features.

\section{SUMMARY AND CONCLUSIONS}

A multi-model ensemble of GCM simulations for recent and future (according to the SRES A1B scenario) climate conditions was investigated with respect to the occurrence of winter storm events over central Europe and their relation to features of large-scale atmospheric circulation. The analysed GCMs were basically capable of reproducing the observed (ERA40) circulation patterns and CWT frequencies for central Europe for the present-day period (20C). Regarding the 2 most frequent winter CWTs, there was a lack of anticyclonic flow (23\% in GCM ensemble mean compared to $31 \%$ of all days in ERA40) and an excess of westerly flow days ( $29 \%$ compared to $23 \%$ ). In the ensemble mean, the frequency of storm events as well as their distribution over flow classes was simulated realistically for both the CWT-related criterion (JC35) and the wind speed percentile-related criterion (SP98). Agreement with observational data was also found for simulated patterns of wind speeds and for characteristics of the associated cyclones during storm days, even when considered according to the CWT during these days.

Under future climate conditions, the atmospheric circulation over Europe is characterised by an increased mean westerly flow during winter. This leads to both a higher frequency of days with westerly flow and to more frequent wind storm days (mainly in coherence with westerly flow). Furthermore, a reduced frequency of cyclonic and easterly flow was detected. The frequency of storm days increases by $19( \pm 28) \%$ for JC35 and $33( \pm 29) \%$ for SP98, respectively. The enhanced storm day frequency is disproportionately high compared to the CWT frequency changes. Cyclones associated with the wind storms show an increased mean intensity of about $10( \pm 10) \%$ over the northeast Atlantic/North Sea region compared to recent climate conditions. The increased number of cyclones occurs in a rather narrow pathway along the eastern Atlantic, British Isles, North Sea to southern Scandinavia. Further, significantly higher wind speeds during storm days of $5( \pm 5) \%$ are detected over large parts of Europe. Even the model showing a reduced frequency of storm days under future climate conditions reveals increased intensity of cyclones and wind speeds in relation to these storm events.

The 2 criteria for the identification of storm days are different by definition. JC35 is based on strength and vorticity of the large-scale geostrophic flow, whereas SP98 is based on the occurrence of extreme surface wind speeds in a central European region representative for the area of Germany. Thus, the 2 identification methods are applied complementarily, and similar results are found for storm days according to both of them, with respect not only to storm day frequencies, but also to associated atmospheric features. Although the sets of identified events differ partly (compare D09), patterns of change signals emerging from the 2 methods are still comparable. The fact that the detected changes are similar even though partly different events are considered indicates some robustness of the identified climate signals.

Our findings are based on a multi-model approach and corroborate recent results based on different analysis methods and mostly single-model analyses (cf. Section 4). Thus, this provides enhanced confidence in previously identified climate change signals, indicating a more zonally large-scale flow over Europe during winter and atmospheric conditions favouring increased risk of winter storms under future climate conditions. 
Acknowledgements. This work was supported by the ENSEMBLES project, funded by the European Commission's 6th Framework Program through contract number GOCECT-2003-505539. We kindly thank ECMWF and DWD (German Weather Service) for ERA-40 data use and availability and DKRZ (German Climate Computing Centre) for storing and providing the ENSEMBLES simulation output. We are grateful to 4 anonymous reviewers, whose useful and constructive comments helped to improve the clarity of the manuscript.

\section{LITERATURE CITED}

Alexandersson H, Tuomenvirta H, Schmith T, Iden K (2000) Trends of storms in NW Europe derived from an updated pressure data set. Clim Res 14:71-73

Bärring L, von Storch H (2004) Scandinavian storminess since about 1800. Geophys Res Lett 31:L20202. doi:10.1029/ 2004GL020441

Benedict JJ, Lee S, Feldstein SB (2004) A synoptic view of the North Atlantic Oscillation. J Atmos Sci 61:121-144

Bengtsson L, Hodges KI, Roeckner E (2006) Storm tracks and climate change. J Clim 19:3518-3543

Christensen JH, Hewitson B, Busuioc A, Chen A and others (2007) Whetton P regional climate projections. In: Solomon S, Qin D, Manning M, Chen Z, and others (eds) Climate change 2007: The physical science basis. Contribution of Working Group I to the Fourth Assessment Report of the Intergovernmental Panel on Climate Change. Cambridge University Press, Cambridge

Collins M (2007) Ensembles and probabilities: a new era in the prediction of climate change. Phil Trans R Soc A 365: 1957-1970

> D'Andrea F, Tibaldi S, Blackburn M, Boer G and others (1998) Northern Hemisphere atmospheric blocking as simulated by 15 atmospheric general circulation models in the period 1979-1988. Clim Dyn 14:385-407

Della-Marta PM, Pinto JG (2009) The statistical uncertainty of changes in winter storms over the North Atlantic and Europe in an ensemble of transient climate simulations. Geophys Res Lett 36:L14703. doi:10.1029/2009GL038557

Demuzere M, Werner M, van Lipzig NPM, Roeckner E (2009) An analysis of present and future ECHAM5 pressure fields using a classification of circulation patterns. Int $\mathrm{J}$ Climatol 29:1796-1810

Donat MG, Leckebusch GC, Pinto JG, Ulbrich U (2009) Examination of wind storms over central Europe with respect to circulation weather types and NAO phases. Int J Climatol (in press) doi:10.1002/joc.1982

Donat MG, Leckebusch GC, Wild S, Ulbrich U (2010) Benefits and limitations of regional multi-model ensembles for storm loss estimations. Clim Res (in press)

Furevik T, Bentsen M, Drange H, Kindem IKT, Kvamsto NG, Sorteberg A (2003) Description and evaluation of the Bergen climate model: ARPEGE coupled with MICOM. Clim Dyn 21:27-51

> Gastineau G, Soden BJ (2009) Model projected changes of extreme wind events in response to global warming. Geophys Res Lett 36:L10810. doi:10.1029/2009GL037500

Hagedorn R, Doblas-Reyes FJ, Palmer TN (2005) The rationale behind the success of multi-model ensembles in seasonal forecasting. I. Basic concept. Tellus 57:219-233. doi:10.1111/j.1600-0870.2005.00103.x

> Huebener H, Cubasch U, Langematz U, Spangehl T, Niehörster F, Fast I, Kunze M (2007) Ensemble climate simulations using a fully coupled ocean-troposphere-stratosphere GCM. Phil Trans R Soc A 365:2089-2101
Johns TC, Durman CF, Banks HT, Roberts MJ and others (2006) The new Hadley Centre climate model (HadGEM1): evaluation of coupled simulations. J Clim 19:1327-1353

> Jones PD, Hulme M, Briffa KR (1993) A comparison of Lamb circulation types with an objective classification scheme. Int J Climatol 13:655-663

> Jungclaus JH, Keenlyside H, Botzet M, Haak H and others (2006) Ocean circulation and tropical variability in the coupled model ECHAM5/MPI-OM. J Clim 19:3952-3972

Klawa M, Ulbrich U (2003) A model for the estimation of storm losses and the identification of severe winter storms in Germany. Nat Hazards Earth Syst Sci 3:725-732

> Knippertz P, Ulbrich U, Speth P (2000) Changing cyclones and surface wind speeds over the North Atlantic and Europe in a transient GHG experiment. Clim Res 15: 109-122

Lambert SJ, Fyfe JC (2006) Changes in winter cyclone frequencies and strengths simulated in enhanced greenhouse warming experiments: results from the models participating in the IPCC diagnostic exercise. Clim Dyn 26: 713-728

Leckebusch GC, Ulbrich U (2004) On the relationship between cyclones and extreme windstorm events over Europe under climate change. Global Planet Change 44: 181-193

> Leckebusch GC, Koffi B, Ulbrich U, Pinto JG, Spangehl T, Zacharias S (2006) Analysis of frequency and intensity of winter storm events from a multi-model perspective, at synoptic and regional scales. Clim Res 31:59-74

> Leckebusch GC, Ulbrich U, Fröhlich L, Pinto JG (2007) Property loss potentials for European midlatitude storms in a changing climate. Geophys Res Lett 34:L05703. doi: 10.1029/2006GL027663

Leckebusch GC, Renggli D, Ulbrich U (2008a) Development and application of an objective storm severity measure for the Northeast Atlantic region. Meteorol Z 17:575-587

Leckebusch GC, Donat MG, Ulbrich U, Pinto JG (2008b) Midlatitude cyclones and storms in an ensemble of European AOGCMs under ACC. CLIVAR Exchanges 13(3):3-5. http://eprints.soton.ac.uk/55670/01/Exch_46_final3.pdf

Legutke S, Voss R (1999) The Hamburg atmosphere-ocean coupled circulation model ECHO-G. Technical report No. 18. German Climate Computer Centre (DKRZ), Hamburg

Manzini E, McFarlane NA (1998) The effect of varying the source spectrum of a gravity wave parameterization in a middle atmosphere general circulation model. J Geophys Res 103:31523-31539

Marti O, Braconnot P, Bellier J, Benshila R and others (2005) The new IPSL climate system model: IPSL-CM4. Note du Pôle de Modélisation, 26. www.ipsl.jussieu.fr/poles/ Modelisation/NotesScience/note26.pdf

> Martin GM, Ringer MA, Pope VD, Jones A, Dearden C, Hinton TJ (2006) The physical properties of the atmosphere in the new Hadley Centre Global Environmental Model (HadGEM1). I. Model description and global climatology. J Clim 19:1274-1301

> Matulla C, Schöner W, Alexandersson H, von Storch H, Wang XL (2008) European storminess: late nineteenth century to present. Clim Dyn 31:125-130

Munich Re (1999) Naturkatastrophen in Deutschland: Schadenerfahrungen und Schadenpotentiale. Munich Re. www. munichre.com/publications/302-01037_de.pdf

Munich Re (2007) Zwischen Hoch und Tief - Wetterrisiken in Mitteleuropa. Edition Wissen, Munich Re. www. munichre.com/publications/302-05481_de.pdf

Murray RJ, Simmonds I (1991) A numerical scheme for tracking cyclone centres from digital data. I: Develop- 
ment and operation of the scheme. Aust Meteorol Mag 39:155-166

Palmer TN, Räisänen J (2002) Quantifying the risk of extreme seasonal precipitation events in a changing climate. Nature 415:512-514

Pinto JG, Spangehl T, Ulbrich U, Speth P (2005) Sensitivities of a cyclone detection and tracking algorithm: individual tracks and climatology. Meteorol Z 14:823-838

Pinto JG, Spangehl T, Ulbrich U, Speth P (2006) Assessment of winter cyclone activity in a transient ECHAM4-OPYC3 GHG experiment. Meteorol Z 15:279-291

Pinto JG, Fröhlich EL, Leckebusch GC, Ulbrich U (2007a) Changing European storm loss potentials under modified climate conditions according to ensemble simulations of the ECHAM5/MPI-OM1 GCM. Nat Hazards Earth Syst Sci 7:165-175

Pinto JG, Ulbrich U, Leckebusch GC, Spangehl T, Reyers M, Zacharias S (2007b) Changes in storm track and cyclone activity in three SRES ensemble experiments with the ECHAM5/MPIOM1 GCM. Clim Dyn 29:195-210

Pinto JG, Zacharias S, Fink AH, Leckebusch GC, Ulbrich U (2009) Factors contributing to the development of extreme North Atlantic cyclones and their relationship with the NAO. Clim Dyn 32:711-737

Pinto JG, Neuhaus CP, Leckebusch GC, Reyers M, Kerschgens M (2010) Estimation of wind storm impacts over West Germany under future climate conditions using a statistical-dynamical downscaling approach. Tellus, Ser A, Dyn Meterol Oceanogr 62:188-201

Raible CC (2007) On the relation between extremes of mitlatitude cyclones and the atmospheric circulation using ERA40. Geophys Res Lett 34:L07703. doi:10.1029/2006GL 029084

Raible CC, Della-Marta PM, Schwierz C, Wernli H, Blender R (2008) Northern hemisphere midlatitude cyclones: a comparison of detection and tracking methods and different reanalyses. Mon Weather Rev 136:880-897

Räisänen J (2007) How reliable are climate models? Tellus 59A:2-29

Editorial responsibility: Filippo Giorgi,

Trieste, Italy
Reichler T, Kim J (2008) How well do coupled models simulate today's climate? Bull Am Meteorol Soc 89:303-311

Reifen C, Toumi R (2009) Climate projections: past performance no guarantee of future skill? Geophys Res Lett 36:L13704. doi:10.1029/2009GL038082

Ringer MA, Martin GM, Greeves CZ, Hinton TJ and others (2006) The physical properties of the atmosphere in the new Hadley Centre Global Environmental Model (HadGEM1). II. Aspects of variability and regional climate. J Clim 19:1302-1326

> Schneidereit A, Blender R, Fraedrich K, Lunkheit F (2007) Iceland climate and North Atlantic cyclones in ERA40 reanalyses. Meteorol Z 16:17-23

> Stephenson DB, Pavan V, Collins M, Junge MM, Quadrelli R, participating CMIP2 modelling groups (2006) North Atlantic Oscillation response to transient greenhouse gas forcing and the impact on European winter climate: a CMIP2 multi-model assessment. Clim Dyn 27:401-420

Tebaldi C, Knutti R (2007) The use of the multi-model ensemble in probabilistic climate projections. Phil Trans R Soc A 365:2053-2075

Ulbrich U, Pinto JG, Kupfer H, Leckebusch GC, Spangehl T, Reyers M (2008) Northern Hemisphere storm tracks in an ensemble of IPCC climate change simulations. J Clim 21:1669-1679

Ulbrich U, Leckebusch GC, Pinto JG (2009) Cyclones in the present and future climate: a review. Theor Appl Climatol 96:117-131

> Uppala SM, Kållberg PW, Simmons AJ, Andrae U and others (2005) The ERA-40 re-analysis. QJR Meteorol Soc 131: 2961-3012

van Ulden AP, van Oldenborgh GJ (2006) Large-scale atmospheric circulation biases and changes in global climate model simulations and their importance for regional climate scenarios: a case study for West-Central Europe. Atmos Chem Phys 6:863-881

- Wang XL, Zwiers FW, Swail VR, Feng Y (2009) Trends and variability of storminess in the Northeast Atlantic Region, 1874-2007. Clim Dyn 33:1179-1195

Submitted: November 6, 2009; Accepted: February 10, 2010 Proofs received from author(s): April 23, 2010 